\title{
A experiência de mapeamento participativo para a construção de uma alternativa cartográfica para a ESF
}

\author{
The experiment of participatory mapping \\ in order to construct a cartographical alternative to the FHS
}

Roberta Argento Goldstein ${ }^{1}$

Christovam Barcellos ${ }^{1}$

M onica de Avelar Figueiredo M afra M agalhães ${ }^{1}$

RenataGracie $^{1}$

Francisco Viacava ${ }^{1}$

${ }^{1}$ Laboratório de

Informações em Saúde, Instituto de Comunicação e Informação Científica e Tecnológica em Saúde, Fundação O swaldo Cruz (ICICT/Fiocruz). Av. Brasil 4365, M anguinhos. 21045-360 Rio de Janeiro RJ roberta@ensp.fiocruz.br
Abstract M apsand mapping proceduresareuseful tools for systematic interpretation and evaluation and for reporting of results to management. Applied to theFamily Health Strategy (FHS), these maps permit the demarcation of the territory and the establishment of links between the territory, its population and health services. In this paper the use of maps by the FHS in 17 municipalities in northern and northeastern Brazil is studied and the process of demarcation and digitization of areas with the participation of teams is de scribed. The survey conducted using questionnaires and discussion workshops showed that difficultiesstill prevail in reconciling themap (drawing) produced at the local level with maps produced by other government sectors. In general, the maps used at local level employ their own references, which prevent the interplay of information with other cartographic documents and their full use as a tool for evaluation and management. The combination of participatory mapping tools, associated with Geographic Information Systems (GIS) applications proposed in this paper, represents an alternative to mapping the territory of operations of FH S teams, as well as a reflection on the concept of territory and operation by theFHS. Key words Participatory mapping, Cartography, Family Health Strategy
Resumo Osmapaseos procedimentos demapeamento são ferramentas úteis para sistematização, interpretação e comunicação de resultados para a gestão eavaliação. A plicadosà Estratégia deSaúde da Família (ESF), estes mapas permitiriam a apropriação do território e o estabelecimento de vínculos entre este território, sua população e os serviços de saúde. N estetrabalho éestudada a utilização demapas pela ESF em 17 municípios das regiões norte enordeste do Brasil e édescrito o processo de delimitação e digitalização das áreas de atuação, com a participação das equipes. 0 levantamento realizado por questionários e a discussão em oficinas demonstraram que ainda persistem dificuldades de compatibilização de mapas (croquis) produzidos no nível local com mapas produzidos por outros setores de governo. Os mapas usados no nível local empregam, em geral, sintaxes próprias, o queimpedea troca deinformações com outros documentos cartográficos e sua plena utilização como instrumento de avaliação e gestão. A combinação de instrumentos de mapeamento participativo, associados às aplicações de Sistemas de Informaç̃ões Geográficas (SIG), proposta nestetrabalho, representa uma alternativa para o mapeamento do território de atuação das equipes da ESF, bem como a reflexão sobre o conceito de território e sua operacionalização pela ESF. Palavras-chave M apeamento participativo, $\mathrm{Car}$ tografia, Estratégia de Saúdeda Família 
Introdução

As atividades de vigilância e atenção à saúde produzem uma grande quantidade de dados que, no entanto, são pouco analisados no nível local. Os problemas encontrados para a espacialização desses dados colaboram para um paradoxo, segundo o qual, as informações produzidas no nível local contribuem para as análises na macroescala, mas são pouco utilizadas nestenível local ${ }^{1}$. Deste modo, os indicadores gerados por esses serviços pouco auxiliam o processo de trabalho de equipes da Estratégia de Saúde da Família (ESF).

À ESF foi creditada possibilidade de aprimorar as diretrizes de universalidade, integralidade, equidade, territorialização edescentralização, pre conizadas pelo Sistema Único de Saúde (SUS). Segundo Costa Neto², a Saúde da Família é entendida como uma estratégia, porque permite a reorientação do modelo de assistência a partir da atenção básica, se difundindo para os demais níveis do sistema de saúde. Por outro lado, possui uma série de características dos programas de saúde propostos anteriormente, como objetivos, metas e normas preestabelecidas. Um dos componentes chaves deste processo é o Agente Comunitário de Saúde (ACS), considerado um elo entrea comunidadee os componentes do sistema de saúde. Contudo, algumas barreiras persistem para a efetivação dessas ações. Segundo Silvaª, os agentes não dispõem de instrumentos tecnológicos e capacitação para a realização das diversas atividades de trabal ho. Logo, há a necessidade de se buscar alternativas, ferramentas emétodos que auxiliem no processo de trabalho dos agentes comunitários de saúdee sua articulação com as equipes, associados a sua realidade local ${ }^{4}$.

Para compreender a atuação dos ACS nas suas áreas de atuação é necessário recuperar o território como categoria geográfica de análise e a sua operacionalização na ESF. 0 marco teórico do território na ESF vem sendo abordado em diversos estudos ${ }^{5-10}$, que salientam a importância da classificação deste território, como um espaço particular, resultante de uma acumulação histórica, cultural, ambiental, e de disputas de poder nele existente. Reconhecer esta dinâmica social e política das áreas de atuação é, portanto, a primeira etapa para um aperfeiçoamento das práticas de trabalho das equipes da ESF nestes territórios.

Nas práticas da ESF podem-se perceber três tipos de relações de poder, que segundo Bitoun ${ }^{10}$ efetivam três tipos de território: um de escuta (na fase de coleta de informações para se atingir a equidade); um administrativo (quando são definidas articulações com outros territórios para garantir o acesso a equipamentos e instituições que permitem uma disponibilidade de recursos mais complexos ou complementares); e um de realizações (quando é materializada a prestação deserviços no espaço vivido). 0 reconhecimento desse território é um passo essencial para a caracterização da população e de seus problemas de saúde, bem como para avaliação do impacto dos serviços de saúde sobre esta população. A efetivação das atividades de atenção à saúde se baseia no entendimento decomo funcionam ese articulam num território as condições econômicas, sociais e culturais e de como se dá a vida das populações, seus atores sociais e a sua íntima relação com seus espaços, seus lugares ${ }^{5}$. A exclusiva referência apenas à quantidade de população para o desenvolvimento de recortes territoriais, sem nenhuma proposta de classificação ou identificação destes territórios, por ações ou problemas de saúde acaba por limitar a eficácia da atuação das equipes da ESF.

O Sistema de Informação sobre Atenção Básica ( $S I A B$ ) é o principal instrumento de coleta, sistematização e recuperação de dados utilizados pelas equipes para cadastro de famílias, acompanhamento da produção executados pela equipe e para a avaliação das condições de saúde dessa populaçãa ${ }^{11}$. Algumas experiências foram re alizadas, ao longo dos últimos anos, de mapeamento de dados do PSF, tais como M ontes Cla$\operatorname{ros}^{8}$, na construção de mapas que permitiram a geração e a visualização de indicadores voltados para a gestão da ESF no nível intraurbano.

Este artigo tem como objetivo demonstrar a contribuição do processo de mapeamento participativo de áreas de atuação das atividades de atenção básica em saúde, apresentando assim uma alternativa cartográfica para a ESF.

O mapeamento participativo surge como uma alternativa para o maior envolvimento da equipe e da população no processo de territorialização.

Neste artigo o termo participação é visto como o processo de sensibilização dos indivíduOS, aumentando-Ihes a responsabilidade para responderem as propostas de programas de de senvolvimento eencorajando iniciativas locais ${ }^{12}$. 0 mapeamento de forma participativa, neste contexto, refere-se amplamente a qualquer mé todo utilizado para obter e registrar dados espaciais em parceria com os atores sociais, neste caso os membros de equipes da ESF. Sendo assim, o mapeamento não inclui apenas um conjunto de ferramentas de visualização de dados, mas um 
processo participativo que envolve os desenvolvedores/usuários dos mapas, desde a coleta esistematização de informação até a confecção destes mapas para auxiliar o processo decisório. Este tipo de mapeamento tem sido amplamente empregado em projetos ambientais tais como: a avaliação do uso do solo em bacias hidrográficas; a definição de áreas de reassentamento de moradores de comunidades; localização de terras indígenas e seringais ${ }^{12}$. De acordo com Ascerald ${ }^{13}$ há 150 casos de experiências classificadas de "mapeamento participativo" identificadas no Brasil, promovidas por ONGs, entidades ambientalistas, entidades associativas de quilombolas, indígenas e outras. $\mathrm{Na}$ área da Saúde podemos destacar o Projeto Saúde e Alegria ${ }^{14}$ desde 1995, que busca promover e apoiar processos participativos de desenvolvimento comunitário, no baixo curso do Rio Tapajós.

A utilidade dos mapas e softwares de geoprocessamento para apresentação e divulgação de dados tem sido reconhecida no âmbito da saúde pública no Brasill15-18, principalmente por demonstrar a informação de maneira sucinta e objetiva alcançando diferentes públicos.

A cartografia considera os mapas como um meio de sistematização e comunicação de dados de natureza espacial. 0 mapa, realidade representada, mantém uma relação com os objetos espaciais representados, baseada em princípios da cartografia, tais como um sistema de signos (sinais ali designados a representar al go da realidade mapeada), a redução (o conceito de escala) eprojeção (desenvolvimento da superfíciedaTerra em um plano) ${ }^{19}$. Qualquer mapaé, portanto, uma simplificação da realidade, que está sujeita aos objetivos e critérios do seu produtor (mapmaker $)^{20}$. As técnicas tradicionais de mapeamento reforçam o distanciamento entre este produtor e o usuário final (mapuser) dos mapas ${ }^{19}$. 0 mapeamento participativo surge como alternativa para a aproximação entre produção e uso dos mapas, reduzindo os vieses de seleção e simplificação dos objetos espaciais, assumidos ao longo do processo de sua criação 20 .

Assim, o mapeamento participativo, pode ser considerado como o processo de espacialização e registro do conhecimento de um dado grupo ou comunidade acerca de uma determinada paisagem ou localidade. 0 resultado de um mapeamento participativo não necessariamente gera mapas segundo as normas da cartografia. Relatos, ilustrações, trajetos, roteiros esquematizados podem ser objetos iniciais ou finais destes mapeamentos. Normalmente esse mapeamento está relacionado tanto às questões ambientais como de ordenamento do território.

A partir da década de 70 pode-se observar uma intensificação de iniciativas de mapeamentos participativos, também chamados de cartografia social, etnocartografia ou mapeamentos humanísticos em diversos países.

A partir de 1990 inúmeras iniciativas mundiais se propuseram a trabalhar com inclusão de populações locais nos processos de produção de mapas. No Brasil, as experiências em cartografia participativa também podem ser observadas em trabal hos decunho socioambiental realizados em comunidades ${ }^{12}$.

A flexibilidade dos procedimentos participativos de mapeamento é outra característica importante, pois se adapta a diferentes contextos e prioridades. Segundo Flavelle ${ }^{21}$, duas estratégias podem ser utilizadas em tarefas que utilizam 0 raciocínio geoespacial:

. "sketch maps" - mapas esquemáticosou croquis é um desenho à mão livre onde se utiliza o conhecimento local para a identificação e representação de objetos espaciais de interesse para uma comunidade. Não requer qualquer tipo de mensuração, cál culo ou técnica cartográfica, possuindo assim, uma baixa acurácia.

. "base maps" - mapas base: são mapas construídos sobre bases cartográficas que possuem referenciais cartográficos e geodésicos, por meio da adição de novas informações sobre diferentes temas. Tem sido utilizado para realizar correlações geográficas, já que permitem a sua sobreposição a outros mapas.

As práticas da ESF estão imbuídas de concepções de território e deterritorialização. A "territorialização" é vista como uma etapa da implantação do PACS e PSF. A ideia de territorialização descrita nos documentos e normas do SUS está baseada em aspectos gerenciais e técnicos ${ }^{21}$. $\mathrm{NaESF}$, o processo deterritorial ização é entendido como a demarcação da área de atuação de unidades básicas desaúde, quedeve coincidir com a área de abrangência das famílias adscritas a esta unidade. Contudo, este processo de territorialização, e delimitação deáreas deatuação, ainda que impreciso ou confuso, é a principal fonte de dados para as análises sociodemográficas no âmbito da ESF ${ }^{21}$. Desta maneira, a fase de planejamento seria o momento adequado para a construção de mapas para o levantamento e a caracterização da população e seu território de moradia. Potencialmente, a delimitação destes territórios teria como vantagem a possibilidade deagregação de dados demográficos, epidemiológicose 
ambientais. Neste trabalho, também buscou-se a correspondência entre o número de pessoas cadastradas nas áreas da ESF, segundo dados do SIAB, eseu número de habitantes, segundo o censo demográfico, para verificar a possibilidade de agregação com outros dados de diferentes bases de dados.

A necessi dade dos agentes de saúde de organizar seu trabal ho no campo para as visitas domiciliares tem estimulado a estruturação de croquis (sketh maps) para a representação de domicílios e áreas de atuação. Segundo Portugal ${ }^{11} 0$ croqui éum breve esboço de um desenho empre gado para posicionar grosseiramente um objeto geográfico em relação ao outro, carecendo de um sistema de coordenadas. Segundo IBGE ${ }^{22} 0$ croqui não obedece a uma rotina técnica para a elaboração de mapas. No presente trabalho, foi usado como modelo os "mapa base - basemaps", tendo em vista a necessidade de inserção de informações adquiridas pela ESF em ambiente de SIG, para o relacionamento com outros dados, advindos de outras fontes de informação.

0 estudo se baseia em dados levantados pelo projeto "Bases cartográficas para o Programa de Saúde da Família" financiado pelo projeto PROESF, que buscou estimular a construção dos mapas das áreas de atuação das equipes da ESF em 17 municípios das regiões norte e nordeste do País, como meio organização do trabalho de campo e para identificar lacunas de cobertura do serviço.

Assim, o presente trabalho apresenta uma alternativa para o mapeamento de áreas de atuação da ESF, tendo como primeiro passo o diagnóstico cartográfico dos mapas pré-existentes, utilizados pelas equipes. Na segunda etapa do trabalho, esses mapas foram compatibilizados com bases cartográficas do censo demográfico, com a participação das equipes e gestores da ESF, visando a sua inserção em ambiente deSIG para aperfeiçoar a capacidade de análise dos dados coletados pelas equipes da ESF.

\section{Metodologia}

Estetrabalho éresultado do projeto PROESF (EXpansão e Consolidação Saúde da Família) realizado em conjunto com a Fundação Cesgranrio, UERJ eFiocruz, econtou com os seguintes objetivos: avaliar a qualidade e o uso pelas equipes da ESF de bases cartográficas existentes, anteriores ao projeto; mapear o território de atuação daESF em conjunto com os coordenares das equipes; e comparar os dados de cobertura e produção da ESF, segundo o SIAB, com os dados do censo demográfico, por meio deferramentas de relacionamento entre camadas em ambiente de SIG.

0 projeto envolveu 17 municípios das regiões norte e nordeste (Ananindeua, Abaetetuba, Be lém, Cametá, M arabá, Santarém, Castanhal, Be lém, M acapá, Caxias, Codó, Imperatriz, São José Ribamar, São Luís, Timon, Araguaina e Palmas), todos com população maior que 100 mil habitantes, segundo critérios estabelecidos pelo projeto PROESF. Na primeira fase do trabalho, foi enviado um questionário e uma planilha, para serem preenchidos pelos coordenadores das equipes da ESF. Este questionário, denominado diagnóstico cartográfico, buscou abordar a existência, as características e a utilização de mapas anteriores a este projeto, enquanto a planilha de atualização levantou informações sobre as áre as, contendo o código usado no SIAB, responsável pela equipe, população atendida, e número devisitas domiciliares (deenfermagem, dos agentes e odontológicas).

A segunda fase do trabal ho se deu diretamente com as equipes por meio de oficinas para a elaboração dos mapas e para a identificação das áreas de atuação. Como instrumento de discussão sobre territorialização e registro dos limites de áreas de atuação, foram usados mapas cadastrais em escala 1:10.000 produzidos pelo IBGE como base para o censo demográfico de 2000.

Nessas oficinas foram discutidas com os coordenadores da ESF questões sobre o processo de delimitação das áreas de atuação das equipes da ESF nos mapas. Sendo assim, foi necessária a revisão de noções sobre croquis e mapas, e SIG. A equipe de geoprocessamento estabeleceu os procedimentos para a confecção de mapas, mas também estimulou as equipes a mostrar suas formas de mapear áreas de atuação. A dinâmica seguiu-se da seguinte forma: i) apresentação dos croquis utilizados pelas equipes do PSF; ii) reconhecimento da área de atuação e locais de refe rência pelos técnicos sobre o mapa base fornecido; iii) identificação dos limites das áreas de atuação e discretização através da codificação do SIAB; iv) digitalização das áreas de atuação. A equipe de geoprocessamento da Fiocruz analisou os mapas produzidos durante as oficinas e realizou os ajustes necessários para sua transcrição para formato digital. Foi usado como padrão de sistema de coordenadas UTM -SAD 69. A digitalização foi feita manualmente utilizando mesa digitalizadora em sistema CAD e foram adequados para utilização em ambiente de SIG. 
As planilhas enviadas também foram digitadas para inserção neste ambiente, er elacionadas com os mapas usando como indexador o código de áreas usado no SIAB.

\section{Resultados}

\section{Diagnóstico cartográfico}

O questionário do diagnóstico cartográfico foi respondido por onze dos dezessete municípios selecionados pelo estudo. A não resposta de al guns municípios em relação à questão cartográfica não representou a retirada destes municípios das etapas posteriores do estudo. A tabelal apresenta 0 resultado do diagnóstico cartográfico.

Cinco dos onzes municípios já utilizavam bases cartográficas digitais, contudo a maior parte desses mapas encontrava-se em sistema CAD, o que impede que sejam utilizadas funcionalidades de SIG, como o vínculo a tabelas, e o relacionamento entrecamadas. D estesmunicípios, somente dois utilizavam esses mapas para demarcação de áreas de atuação da ESF, demonstrando a pequena incorporação tecnológica no setor saúde no que diz respeito à ESF. Outros municípios, que possuíam mapas em formato analógico (papel) utilizavam essas bases para a delimitação de área de atuação da ESF. Contudo, nem todos esses mapas analógicos possuem referenciais cartográficos, o que dificulta o processo de inserção no SIG e a posterior análise de dados.

Osobjetos geográficosmais representadosnos mapas foram os arruamentos e rios, que em geral são usados como referencias para a delimitação das áreas. Os rios são particularmente im- portantes no contexto da Amazônia (10 municípios), onde é muito frequente este acidente geográfico no interior das cidades. Apenas 6 municípios declararam possuir mapas com a localização de unidades de saúde, que, no entanto, constitui um objeto geográfico relevantepara a delimitação das áreas de abrangência e a avaliação das condições de acesso da população a este serviço. As áreas verdes são citadas no questionário por apenas 2 municípios. 0 mapeamento de áreas verdes poderia auxiliar na identificação de áreas pouco povoadas e barreiras de acesso, principalmente na região amazônica.

\section{Delimitação de áreas}

O processo de construção dos mapas com as áreas de atuação seguiu em geral as etapas de: identificação de locais de referência, que foram usados pelas equipes para se reconhecer no mapa, por meio de construções, acidentes geográficos ou ruas; verificação e marcação no mapa dos trajetos percorridos por agentes de saúde, e delimitação das áreas, estabelecendo e revendo as ruas cobertas por cada equipe da ESF. A Figura 1 apresenta o processo de reconhecimento dos mapas base e a delimitação das áreas.

Durante o processo de mapeamento os participantes foram incentivados a refletir sobre a importância do trabalho da elaboração mapas para a territorialização das ações de saúde das equipes da ESF. Neste processo, foram verificadas diferentes noções de território e sua expressão cartográfica, o que teve consequências sobre o significado e a representação de áreas e microáreas de atuação. Os diferentes entendimentos de território e área foram observados nos pri-

Tabela 1. Características cartográficas dos mapas usados pelas equipes da ESF nos municípios do norte e nordeste estudados pelo projeto PROESF.

\begin{tabular}{lcccccc}
\hline \multicolumn{1}{c}{ Municípios } & $\begin{array}{c}\text { Formato } \\
\text { dos mapas }\end{array}$ & Escala & Norte & $\begin{array}{c}\text { Sistema de } \\
\text { Coordenadas }\end{array}$ & $\begin{array}{c}\text { Demarcação } \\
\text { área de atuação }\end{array}$ & $\begin{array}{c}\text { Limites com } \\
\text { bairros e distritos }\end{array}$ \\
\hline Araguaina & digital & $\operatorname{sim}$ & $\operatorname{sim}$ & $\operatorname{sim}$ & não & não \\
Timon & analógico & não & não & não & sim & sim \\
São José do Ribamar & analógico & não & não & não & sim & sim \\
Caxias & analógico & $\operatorname{sim}$ & $\operatorname{sim}$ & $\operatorname{sim}$ & não & não \\
Codó & digital & $\operatorname{sim}$ & não & $\operatorname{sim}$ & não & sim \\
São Luis & analógico & não & $\operatorname{sim}$ & não & sim & sim \\
Imperatriz & analógico & $\operatorname{sim}$ & $\operatorname{sim}$ & $\operatorname{sim}$ & $\operatorname{sim}$ & sim \\
Santarém & digital & $\operatorname{sim}$ & $\operatorname{sim}$ & $\operatorname{sim}$ & sim & não \\
Marabá & digital & $\operatorname{sim}$ & $\operatorname{sim}$ & $\operatorname{sim}$ & não & não \\
Castanhal & analógico & $\operatorname{sim}$ & $\operatorname{sim}$ & não & sim & sim \\
Belém & digital & $\operatorname{sim}$ & $\operatorname{sim}$ & $\operatorname{sim}$ & sim & sim \\
\hline
\end{tabular}




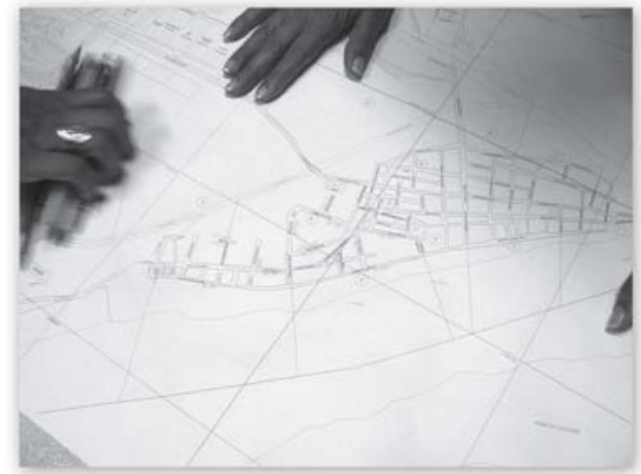

Identificação de locais de referência

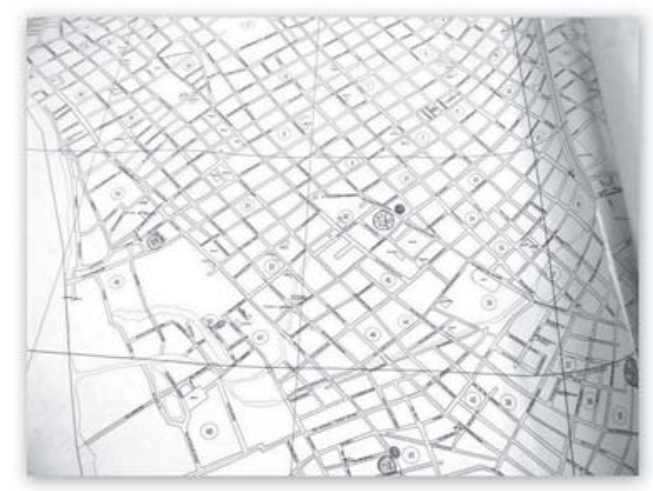

Localização de unidades de saúde

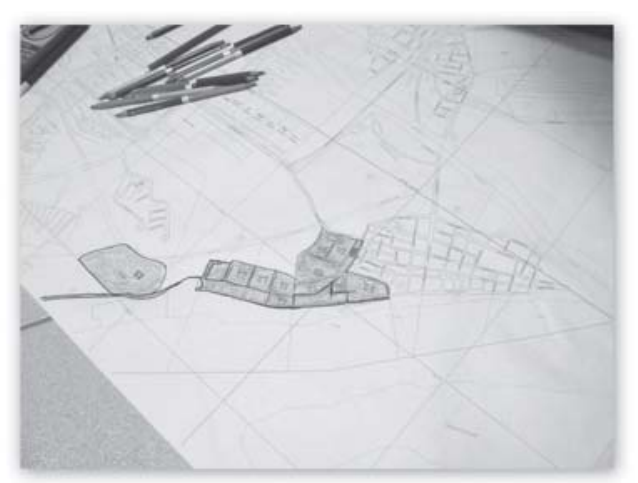

Identificação dos limites de áreas de atuação

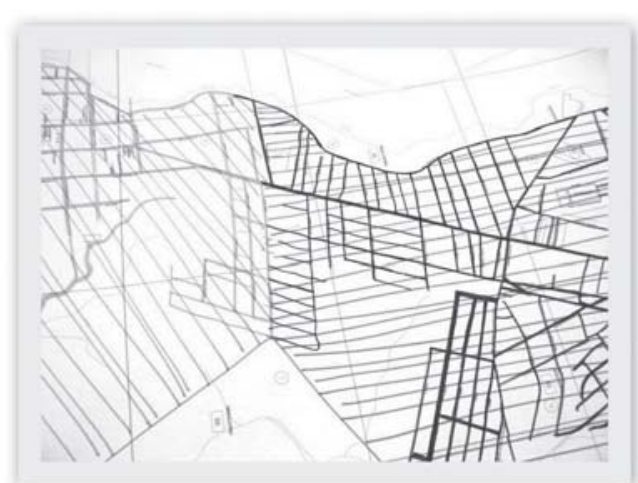

Identificação dos trajetos das equipes nas áreas de atuação

Figura 1. Processo de construção dos mapas base e delimitação de áreas.

meiros traçados executados pelas equipes. Em alguns casos a área foi representada por um ponto, marcando a localização da unidade básica de saúde, com a identificação das equipes por meio de círculos com cores. Em outros casos a área foi representada pelas linhas, marcando as ruas percorridas pelos agentes. N estes casos, foi necessário ressaltar a importância de demarcação dos limites das áreas de atuação da ESF. Após o desenho das áreas, foram verificados problemas de sobreposição, isto é, domicílios co bertos por duas equipes, bem como vazios, isto é, domicílios localizados entre duas áreas que não eram cobertos pelas equipes. A existência de áreas não cobertas ou sobrepostas evidenciou que a população cadastrada na ESF nem sempre corresponde com a população adscrita, residente nas áreas de abrangência.
Este procedimento demonstrou que o dese nho de áreas sobre mapas censitários pode auxiliar no processo de planejamento, estruturação e distribuição das equipes pelas áreas, ou seja, o mapeamento assumiu uma inegável importância no processo de organização de trabalho das equipes da ESF.

A experiência da aplicação de SIG na identificação das áreas de ESF

N este trabalho, buscou-se avaliar a cobertura das equipes da ESF, comparando-se duas metodologias para estimativa de população: $O$ cadastro da população adscrita, segundo dados do SI AB, e o total de população residentenasáreas cobertas, calculado segundo dados do censo demográfico de 2000. Utilizando-se ferramentas de SIG, foram 
sobrepostas as camadas de mapas das áreas da ESF à camada dos setores censitários.

Esta operação demonstrou a baixa coincidência cartográfica entre os limites das áreas da ESF e os setores censitários. Para unidades espaciais maiores, como o bairro e o distrito, esta coincidência é maior, isto é, as áreas da ESF tendem a não ultrapassar os limites de bairros e distritos. Isso pode ocorrer devido ao modelo deterritorialização proposto pela ESF, realizado com base na proximidade às unidades de Saúde. Nem todos os municípios brasileiros possuem bairros

Tabela 2. Comparação entre metodologias de estimativa de cobertura para o PSF (s/i, sem informação).

\begin{tabular}{lccc}
\hline \multirow{2}{*}{$\begin{array}{c}\text { Município } \\
\end{array}$} & UF & \multicolumn{2}{c}{ Cobertura (\%) } \\
\cline { 3 - 4 } & & $\begin{array}{r}\text { Segundo } \\
\text { oSIAB }\end{array}$ & $\begin{array}{c}\text { Segundo } \\
\text { o Censo }\end{array}$ \\
\hline Abaetetuba & PA & 11,0 & 14,6 \\
Araguaina & TO & 60,3 & 79,2 \\
Castanhal & PA & 71,6 & 41,4 \\
Caxias & M A & 100,0 & 98,0 \\
Codó & M A & 36,7 & 69,0 \\
Macapá & AP & 24,9 & 29,6 \\
Marabá & PA & 3,8 & 2,2 \\
Palmas & TO & 76,1 & 63,1 \\
Santarém & PA & 18,0 & 36,0 \\
Belém & PA & 17,2 & $\mathrm{~s} / \mathrm{i}$ \\
São Luis & M A & 23,5 & $\mathrm{~s} / \mathrm{i}$ \\
Timon & M A & 100,0 & $\mathrm{~s} / \mathrm{i}$ \\
\hline
\end{tabular}

instituídos e reconhecidos oficialmente, o que dificulta a aquisição de bases cartográficas digitais de bairros.

A comparação entre as estimativas de população coberta segundo as duas metodologias ( Tabela 2) permitiu evidenciar diferenças que podem ser resultado de incorreções no processo de adscrição da população.

Em geral, as coberturas estimadas usando dados do censo são superiores àquelas calculadas segundo dados do SIAB, com exceção de Castanhal e Palmas. A diferença entre estimativas apresentou erro médio de 13,9\% eum desvio padrão de 9,8\%. Como exemplo, o município de Araguaína apresenta segundo dados do SI AB cerca de $60,3 \%$ da população urbana coberta pela ESF. A superfície dos setores censitários coberta pelas áreas da ESF é de 39,0 km², o que correspondesegundo o censo a 83.427 habitantes, aproximadamente $79,2 \%$ da população urbana do município. Como a população coberta pela ESF é menor que a população residente, pode-se levantar a hipótese da existência de vazios e domicílios não cadastrados, mesmo aqueles contidos nas áreas da ESF.

A comparação entre os mapas de setores censitários e as áreas da ESF permitiu a análise da distribuição das equipes segundo nível de renda da população. Em geral as áreas da ESF se concentram em locais de baixa renda. No entanto, de acordo com a Figura 2, em municípios como Ananindeua observa-se quea ESF cobre mais da metade da superfície do município, porém, as

\section{a}

b

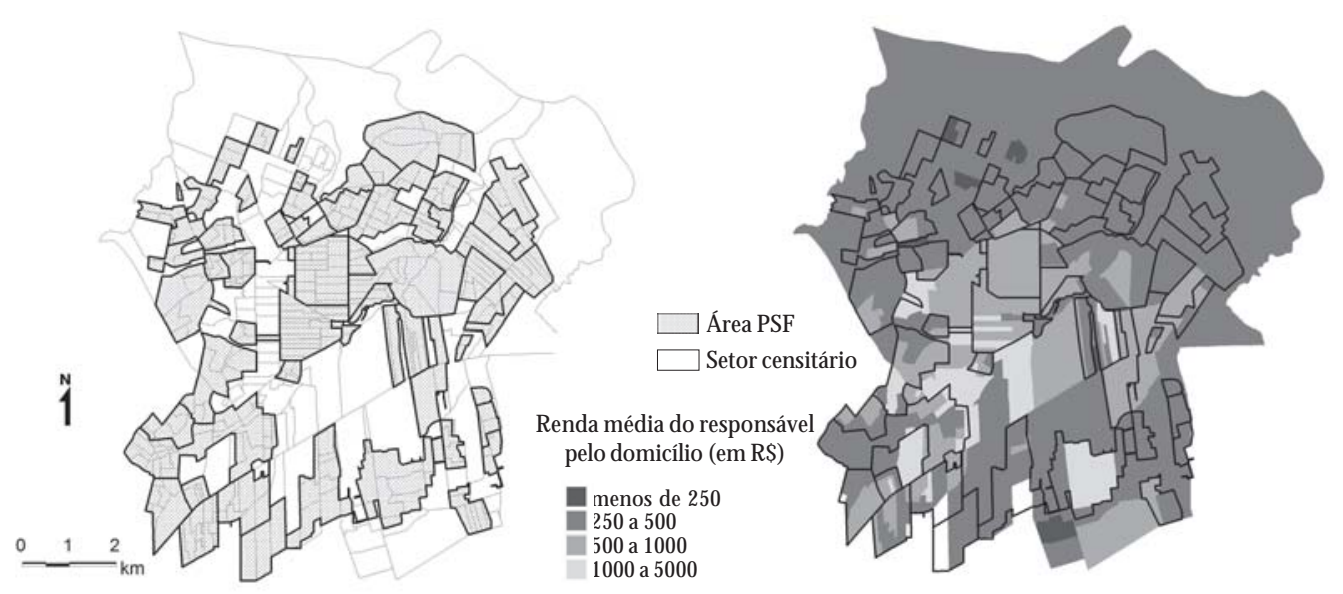

Figura 2. Sobreposição das áreas de atuação das equipes da ESF e distribuição espacial da renda média do responsável pelo domicílio. 
áreas mais carentes estão descobertas. A ESF se concentra em áreas onde a população tem renda média entre $R \$ 200$ a 1000.

Pode-se verificar por meio destes exemplos, a insuficiência dos dados gerados pelo SI AB para o diagnóstico do território da totalidade do município. A integração dos dados do SIAB com os do censo, por meio de ferramentas de SIG, ajuda a planejar e a priorizar ações e locação de recursos.

Asprincipaisfunções do SI G são a integração e a espacialização de dados. Neste estudo, buscou-se representar a distribuição das taxas de visitas domiciliares nos municípios. Conforme apresentado na Figura 3, observou-se que as atividades mais frequentes da ESF são visitas de agentes de saúde, enquanto as consultas são pre dominantemente para atendimentos odontológicos. No município de Araguaína, a distribuição espacial destas atividades é semelhante, isto é, locais com maior frequência de visitas são também geradores de mais consultas, o que pode permitir avaliar o trabalho das equipes e sua complementaridade.

Durante as oficinas foi possível avaliar todo material cartográfico reunido nos municípios junto com os mapas do IBGE e elaborar proce dimentos de aquisição de dados a partir da disponibilização das bases cartográficas, segundo as diferentes situações dos municípios. O Quadro 1, síntese, apresenta um resumo das principais situações encontradas no decorrer do projeto e os procedimentos utilizados para a ade quação dos mapas existentes a um SIG.

As sugestões de procedimentos listadas no quadro permitem o aprimoramento das práticas de mapeamento para a ESF em outros municípios, principalmenteaqueles em fasedeimplantação ou expansão.
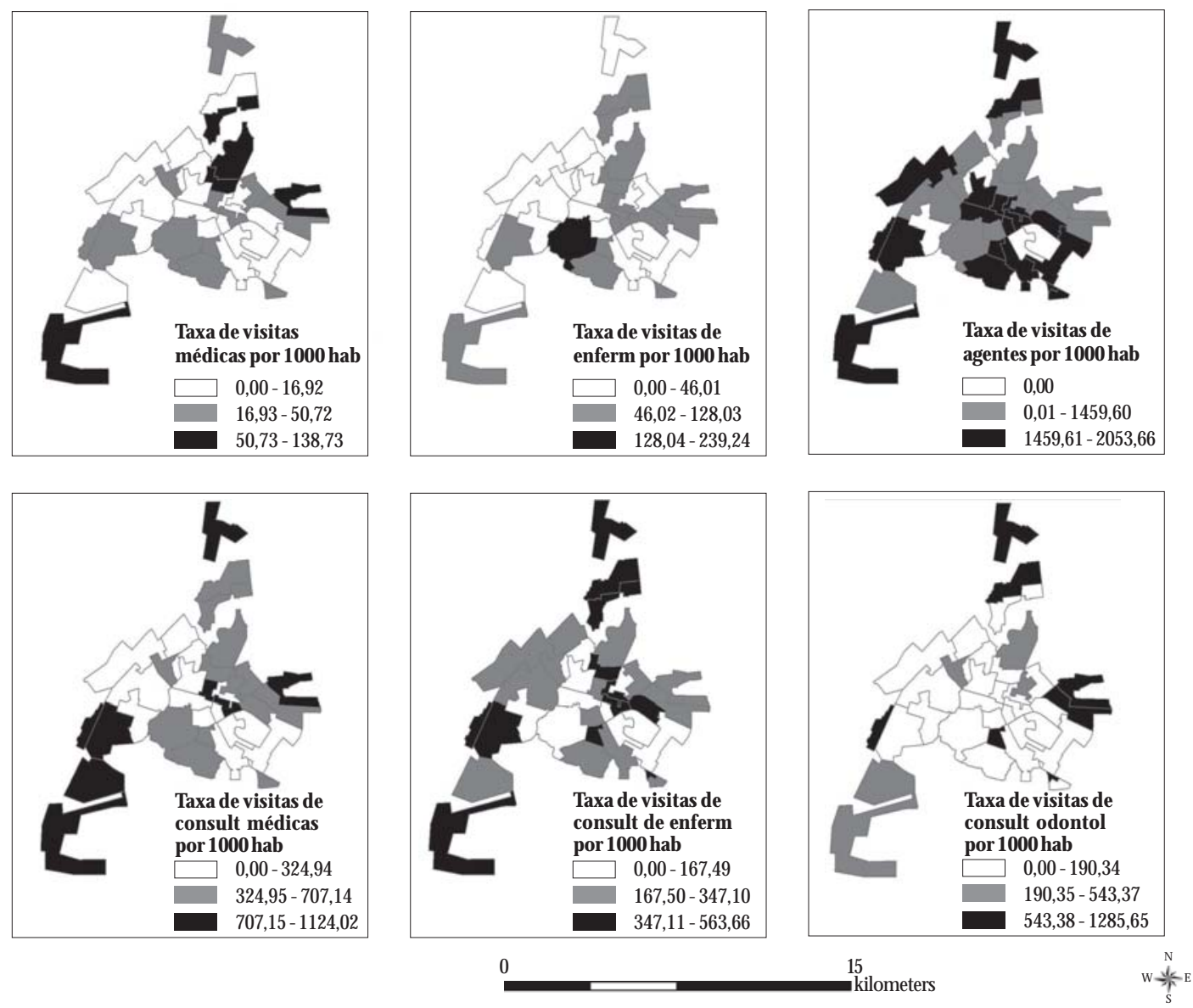

Figura 3. Distribuição das taxas de visitas e consultas para o segundo semestre 2005.

Fonte de dados: Coordenação do PSF; Digitalização: Laboratório de Geoprocessamento - SI GFIOCRUZ eI BGE; Estruturação dos mapas: Laboratório de Geoprocessamento - SIGFIOCRUZ 
Quadro 1. Síntesecom resumo das princi pais situações encontradas no decorrer do projeto eos procedimentos utilizados para a adequação dos mapas existentes a um SI G.

\begin{tabular}{|l|l|l|}
\hline \multicolumn{1}{|c|}{$\begin{array}{c}\text { Situações possíveis em } \\
\text { relação a base cartográfica }\end{array}$} & \multicolumn{1}{|c|}{ Procedimentos } & \multicolumn{1}{|c|}{$\begin{array}{c}\text { que fazer em relação a } \\
\text { delimitação da área do PSF }\end{array}$} \\
\hline $\begin{array}{l}\text { Base cartográfica digital } \\
\text { sem delimitação das áreas } \\
\text { do PSF }\end{array}$ & $\begin{array}{l}\text { Imprimir base cartográfica de ruas; } \\
\text { Escolher uma cor para cada agente } \\
\text { Marcar a unidade de saúde }\end{array}$ & $\begin{array}{l}\text { Percorrer as ruas de cada agente. } \\
\text { Utilizar acidentes geográficos ou } \\
\text { objetos geográficos para fechar } \\
\text { as áreas. }\end{array}$ \\
\hline $\begin{array}{l}\text { Base cartográfica em papel } \\
\text { com áreas do PSF } \\
\text { delimitadas* }\end{array}$ & $\begin{array}{l}\text { Pré definir uma cor para cada agente. } \\
\text { Verificar se não há áreas ou agentes } \\
\text { sobrepostas. }\end{array}$ & $\begin{array}{l}\text { Já está delimitada, buscar o } \\
\text { processo de digitalização e } \\
\text { adequação para sistema SIG }\end{array}$ \\
\hline $\begin{array}{l}\text { Base cartográfica em papel } \\
\text { sem delimitação das áreas } \\
\text { do PSF;* }\end{array}$ & $\begin{array}{l}\text { Pré definir uma cor para cada agente } \\
\text { Verificar se não há áreas ou agentes } \\
\text { sobrepostas. } \\
\text { Marcar a unidade de saúde }\end{array}$ & $\begin{array}{l}\text { Percorrer as ruas de cada agente. } \\
\text { Utilizar acidentes geográficos ou } \\
\text { objetos geográficos para fechar } \\
\text { as áreas. }\end{array}$ \\
\hline $\begin{array}{l}\text { Croqui com áreas do PSF } \\
\text { delimitadas* }\end{array}$ & $\begin{array}{l}\text { Pré definir uma cor para cada agente } \\
\text { Verificar se não há áreas ou agentes } \\
\text { sobrepostas. } \\
\text { Marcar a unidade de saúde }\end{array}$ & $\begin{array}{l}\text { Já está delimitada, buscar o } \\
\text { processo de digitalização e } \\
\text { adequação para sistema SIG }\end{array}$ \\
\hline $\begin{array}{l}\text { Croqui sem delimitação } \\
\text { das áreas do PSF* }\end{array}$ & $\begin{array}{l}\text { Pré definir uma cor para cada agente } \\
\text { Verificar se não há áreas ou agentes } \\
\text { sobrepostas. } \\
\text { Marcar a unidade de saúde }\end{array}$ & $\begin{array}{l}\text { Percorrer as ruas de cada agente. } \\
\text { Utilizar acidentes geográficos ou } \\
\text { objetos geográficos para fechar } \\
\text { as áreas. }\end{array}$ \\
\hline $\begin{array}{l}\text { *Buscar ajuda nassecretarias estaduaisou municipais deurbanização emeio ambiente para verificar a existência demapas } \\
\text { digitais ou a possibilidade de digitaçáo dos mapas analógicos. } \\
\text { censitários ou na prefeitura mapa de rua }\end{array}$ & Seguir a metodologia do artigo \\
\hline
\end{tabular}

\section{Discussão}

Como todas as estratégias de participação, os métodos de mapeamento devem ser adaptados ao contexto eaos interesses locais. 0 processo de integração do mapeamento participativo ao SI G se mostra relevante para diversas variedades de projetos no âmbito da saúde, quando o objetivo é reunir informações sobre as áreas de atuação do setor no nível local e apresentá-las de forma mais eficaz aos gestores locais ou à comunidade. 0 principal problema encontrado na confecção dos mapas participativos foi decorrente do seu uso restrito aos agentes ou equipes. M uitas vezes, esses mapas são considerados apenas desenhos, elaborados e destinados ao uso interno da ESF com pouca capacidade de diálogo com outras instâncias do SUS ou outros setores. Estes mapas, produzidos por leigos e no nível local, não são considerados relevantes para os tomadores de decisão dosníveis municipal e estadual. Esteé um problema recorrente nas abordagens participativas, que são ainda tidas como de pouca relevância científica. 0 uso do mapeamento participativo como uma ferramenta multidisciplinar de empoderamento e de gestão do território ainda é um desafio no meio acadêmico ${ }^{12}$.

O processo de construção de croquis pelas equipes da ESF demonstra a pouca familiaridade com conceitos e técnicas de cartografia. Entendese por alfabetização cartográfica o processo de aprendizagem, desde a estruturação até a leitura de produtos cartográficos (croqui, mapas, etc.). No caso das equipes da ESF, o croqui é visto apenas como um processo de representação, comunicação interna e visualização de objetos geográficos de interesse para a organização do trabalho destas equipes. Em decorrência desta concepção, 
não são consideradas as normas cartográficas, como semiologia gráfica (relação entre os símbolos e os objetos geográficos representados) e escala (relação entreo mapa eo terreno). Esteestudo permitiu identificar vulnerabilidades no processo atual de produção de mapas pela ESF. Os mapas existentes na maior parte dos municípios estudados têm como objetivo o registro de dados e a organização do trabalho dos agentes. Deste modo, possui pequena capacidadedeenvolvimento da equipe com os gestores municipais e com a população. Os mapas não acompanham as mudanças realizadas na criação ou alteração das áre as, já que o croqui é estático e impede o registro da memória destas alterações, com um grande risco de perda de dados quando da substituição deum agente. Utilizando croquis, a incorporação de novos dados sociais e ambientais, produzidos por outros setores de governo fica comprometida, demonstrando que não são ferramentas ade quadas para a visualização e a análise de indicadores gerados pelo próprio sistema de informação da ESF, o SIAB.

0 que se pretendeu nestetrabalho foi demonstrar a possibilidade de se incorporar abordagens participativas de mapeamento aos SIG, na busca deuma maior visibilidadee entendimento da dinâmica do social da saúde nos territórios de atuação das equipes da ESF.

Torna-se necessário que a análise das informações do mapeamento seja realizada pelos membros das equipes da ESF. Contudo, essa análise se tornaria restrita se realizada por espe cialista. Há a necessidade de se buscar capacitação dos membros de equipes da ESF, tanto para o processo de avaliação, como para o levantamento de dados objetivos e subjetivos feito pelas comunidades envolvidas.

É inegável a importância hoje adquirida pe los mapas em conformidade com as normas cartográficas. A popularização de ferramentas de geoprocessamento (Google Earth, por exemplo) edemapas digitais acessíveis na Internet, pressupõe que todos os dados espaciais sigam padrões universais de produçãa e disponi bilização. Contudo, é importante reconhecer que aqueles produzidos pelas comunidades abarcam uma maior diversidadena apresentação de conteúdos, que são extremamente relevantes para a gestão territorial. Sendo o mapa produzido pelos agentes um documento que visa transmitir informações dos territórios de atuação para sua equipe, este deve ser elaborado de acordo com as normas de sintaxe da cartografia, para que seja coerente com os outros produzidos pelos demais setores. A ela- boração e a interpretação de mapas pelas equipes da ESF éum processo de comunicação gráfica, queleva em consideração o entendimento dos profissionais de saúde sobreseu território de atuação. Segundo Rodrigues e Souza ${ }^{23}$, a comunicação a partir da cartografia deve ser vista como um processo monossêmico de transmissão da informação onde o emissor e o receptor, são os atores da ação e juntos devem visar o mesmo objetivo: a compreensão das relações que seestabelecem entre os signos.

0 método cartográfico não pode ser considerado como meramente descritivo, mas sim como instrumento de análise, interpretação, comunicação e construção de cenários. 0 mapeamento permite realizar a síntese, se aproximando e reconstruindo a totalidade do espaço geográfico. A expressão do território em mapas é condicionada à própria coleta e sel eção de informações. Além disso, o uso de mapas estimula a aprendizagem sobre as interações humanas e os objetos geográficos. Pode-se destacar como re sultado pedagógico deste estudo, o entendimento do processo de construção dos mapas base para a demarcação das áreas de atuação e a re conceituação de território pelas equipes.

A integração entre as ferramentas de geoprocessamento e o mapeamento participativo permite incorporar dados secundários, obtidos por meio de banco de dados de agências (condições de habitação; infraestrutura urbana, condições epidemiológicas e ambientais) a informações produzidas no campo (organização do território; objetos geográficos de interesse para a comunidade, recursos e riscos percebidos). É no intuito de maximizar o potencial de análise ecomunicação dos mapas produzidos pela ESF, sem prejudicar a expressão das subjetividades de cada equipe, mas em conformidade com os critérios de representação gráfica em cartografia.

A ESF objetiva a intervenção junto à população no seu território, como campo de práticas, por meio de ações abrangentes de promoção, prevenção, assistência e recuperação da saúde. 0 seu principal desafio é integrar estas diversas práticas, o que pode ser potencializado pelo mapeamento epela participação social no contexto ambiental, social ecultural em que as ações de saúde acontecem. A estratégia combinada de mapeamento, proposta neste estudo pode servir como base para o desenvolvimento de ações intra e intersetoriais a partir da ESF. 0 processo de reconhecimento do território de atuação das equipes da ESF deve refletir as novas maneiras de realizar o trabalho em saúde, em situações concretas que 
contribuam para produção da saúde. Assim como o mapa busca representar o território, seu processo de confecção e interpretação demonstra a apropriação deste pelas equipes da ESF.

\section{Colaboradores}

RA Goldstein, C Barcellos, M AFM M agalhães, R Gracie e $F$ Viacava participaram igualmente de todas as etapas de elaboração do artigo.

\section{Referências}

1. Barcellos C, Ramalho WM, Gracie R, M agal hães M M, Skaba D. Georreferenciando dados de saúde em uma escala submunicipal. Algumas experiência no Brasil. Epidemiol. Serv. Saúde 2008; 17(1):59-70.

2. Costa Neto MM, organizador. A implantação da unidade de saúde da família. In: Brasília: M S; 2000. Cadernos de atenção Básica.

3. Silva JA. O agente comunitário de saúde do Projeto QUALIS: agente institucional ou agente de comunidade? [tese] São Paulo: Universidade de São Paulo; 2001.

4. Papinutto AS. O Território na construção do conhecimento local na Estratégia da Saúde da Família: 0 caso do município de Petrópolis [tese]. Rio de Janeiro: ENSP; 2011.

5. M onken $M$, Barcellos $C$. Vigilância em saúde e território utilizado: possibilidades teóricas e metodológicas. Cad Saude Publica 2005; 21(3):898-906.

6. Riceto A, Silva VP. Território como categoria de análise da geografia. Caminhos de Geografia U berlândia 2008; 9(28):146-152.

7. Pereira R, Paranhos LS. Utilização do Cadastro Técnico Multifinalitário no M apeamento de Condições de Saúde - a experiência do município de M ontes Claros/M G. Informatica Pública. [acessado 2012 nov 3]. Disponível em: http://www.ip.pbh.gov. br/ANO4 N1 PDF/ip0401pereira.pdf

8. Pereira M PB, Barcellos C. O território no programa de saúde da família. Hygeia 2006; 2(2):47-55.

9. Gondim G, Monken M, Rojas LI, Barcellos C, Peiter $P, N$ avarro M BMA, Gracie R. 0 território da Saúde, a organização do sistema de saúde e a territorialização. In: M iranda AC, Barcellos C, M oreira J, Monken M, organizadores. Território, Ambiente e Saúde. Rio de Janeiro: Fiocruz; 2008. p. 237-255.

10. Bitoun J. A política de saúde e as inovações na gestão local. Cidadania, cidade é notícia. ETAPAS 2000; 4:Abril/M aio.

11. Portugal JL. Sistema de informações geográficas para o Programa de Saúde da Família [tese]. Recife: Escola Nacional de Saúde Pública, Fundação Oswaldo Cruz; 2003. 
12. Argento RG, Barcellos C. Geoprocessamento e Participação Social: ferramentas para vigilancia ambiental em saude. In: Carvalho de Miranda A, Barcellos C, M oreira J, M onken M, organizadores. Território, Ambiente e Saúde. Rio de Janeiro: Fiocruz; 2008. p. 205-216.

13. Ascerald H. Cartografias Sociais e Território. Rio de Janeiro: Editora do Instituto de Planejamento U rbano e Regional (IPPUR), U niversidade Federal do Rio de Janeiro (UFRJ); 2008.

14. Projeto Saúde e Alegria (PSA). 2010 [acessado 2012 nov 4). Disponível em: http://www.saudeealegria. org.br/index.php

15. Rojas LI, Barcellos C, Peiter P. Utilização de mapas no campo da Epidemiologia no Brasil: reflexões sobre trabalhos apresentados no IV Congresso Brasileiro de Epidemiologia. Inf. Epidemiol. Sus 1999, 8(2):27-35.

16. Câmara G, M onteiro AM V. Geocomputation techniques for spatial analysis: are they relevant to health data? Cad Saude Publica 2001; 17(5):1059-1071.

17. Carvalho MS, Souza-Santos R. Análise de dados espaciais em saúde pública: métodos, problemas, perspectivas. Cad Saude Publica 2005; 21(2):361-378.

18. Girardi G. Leitura de mitos de mapas: um caminho para repensar as relações entre Geografia e Cartografia. Geografares 2000; 1(1):41-50.

19. Monmonier M. How to lie with maps. Chicago: University of Chicago Press; 1996.

20. Bezerra ACV, Bitoun J. Debatendo o Espaço Geográfico: contribuições a partir do Programa de Saúde Ambiental do Recife. In: Sá AJ, Corrêa ACB, organizadores. Regionalização e Análise Regional. Recife: Editora Universitária da UFPE; 2006. p. 47-63.

21. Flavelle A. M apping our land. A guide to making maps of our own communities \& tradiotional lands. Greenwich: Lone Pine Foundation; 2002.

22. Instituto Brasileiro de Geografia e Estatística (IBGE). N oções Básicas de cartografia. Rio de Janeiro: IBGE; 1993.

23. Rodrigues SC, Souza LHF. Comunicação Gráfica: Bases Conceituais para 0 entendimento da linguagem cartográfica. Espaço \& Tempo Geousp 2008; 23: 65-76.

Artigo apresentado em 12/11/2011

Aprovado em 10/03/2012

Versão final apresentada em 24/04/2012 